\title{
Outline of an Automated System for the Quasi-Continuous Measurement of Particle-size Distribution
}

\author{
${ }^{1}$ A. NEMES, ${ }^{2}$ I. CZINKOTA, ${ }^{3}$ Gy. CZINKOTA, ${ }^{2}$ L. TOLNER and ${ }^{4}$ B. KOVÁCS \\ ${ }^{1}$ Research Institute for Soil Science and Agricultural Chemistry (RISSAC) of the \\ Hungarian Academy of Sciences, Budapest, ${ }^{2}$ Szent István University, Department of \\ Soil Science and Agricultural Chemistry, Gödöllö, ${ }^{3}$ ALTAIR Bt., Fót and ${ }^{4}$ University \\ of Miskolc, Department of Hydrogeology and Engineering Geology, Miskolc (Hungary)
}

Environmental problems do not respect manmade national boundaries and therefore demand international co-operation to find solutions. Often, these solutions require the ability to use soil data as input in simulation models. Soil water and solute transport models need soil hydraulic data as input. Measurements to obtain soil hydraulic data are time-consuming and costly, so for many applications, the prediction of these properties by pedotransfer functions (PTFs) can be a competitive alternative.

Particle-size distribution (PSD) is a fundamental physical property of soils, correlated to many other soil properties. As there is continued interest in predicting more complex soil physical and chemical properties from easily measured soil characteristics it also became a key input parameter to the PTFs. Different methods exist and are applied to determine soil PSD. GEE \& BAUDER (1986) describe the principles of the most basic and widely used methods. Alternative methods have been developed and proposed by e.g. STUYT (1992); OLIVEIRA et al. (1997) and STARR et al. (2000). Despite a number of recognized international standards, soil texture data are rarely compatible across national frontiers, which makes it difficult to use such data. Most existing PTFs adhere to the FAO/USDA system. FAO (1990) and USDA (1951) define clay as the particle-size fraction $<2 \mu \mathrm{m}$, silt as the fraction between 2 and $50 \mu \mathrm{m}$ and sand as the fraction between 50 and $2000 \mu \mathrm{m}$. NEMES et al. (1999), however, give an example for countries where soils are classified in a different manner. In most of those cases, the silt/sand boundary is defined differently - at $20 \mu \mathrm{m}$ - as adopted by the International Society of Soil Science (ISSS, 1929). Other systems also exist, e.g. that applied in the STATSGO database in the United States (Soil Survey Staff, 1991) - which has a lower cut-off limit for sand at $74 \mu \mathrm{m}-$

Correspondence to: Attila NEMES, Research Institute for Soil Science and Agricultural Chemistry (RISSAC) of the Hungarian Academy of Sciences, H-1022 Budapest, Herman Ottó út 15. E-mail: bloro@spike.fa.gau.hu 
or that of KATCHINSKI (1956) that is widely applied in the Central and Eastern region of Europe. Latter system defines clay as the mass fraction of particles smaller than $1 \mu \mathrm{m}$ and defines the upper cut-off limit for sand at $3000 \mu \mathrm{m}$. FILEP \& FERENCZ (1999) give an overview on existing soil textural categorization systems. They establish empirical relationships between particle-size distribution data and other related soil physical properties that are used in soil textural classification in Hungary. They recommend the revision of the proposed systems, once more detailed particle-size data will become available.

Currently, standardization of particle-size description offers the only solution to achieve compatibility of soil data among various systems. Several studies suggest that the particle-size distributions (PSD) in soils show an approximately lognormal distribution (CAMPBELL, 1985; SHIRAZI \& BOERSMA, 1984). However, soils with bimodal particle-size distributions also do occur (WALKER \& Chittleborough, 1986). Buchan (1989) described the applicability of lognormal models for particle-size distributions and found that these are only applicable for about half of the USDA soil texture classes (Soil Survey Staff, 1975). He also discussed the effects of the number of particle-size fractions that are measured on the shape of the cumulative PSD curve. The more complex the cumulative distribution is, the greater the number of required model parameters is. ROUSSEVA (1987) applied two different techniques (graph and polynomial fit) to transform particle-size distributions from KATCHINSKI's (1956) texture scheme to the scheme used by the United States Department of Agriculture (USDA) (Soil Survey Staff, 1975). She concluded that polynomial fits do not convert soil texture data adequately and that use of graphs is better, even though it is time- and labour-consuming and subjective. RousSEVA (1997) defined closed-form models of exponential and power law. She investigated the suitability of these models to fit cumulative particle-size distributions of different shapes and with varying numbers of measured points. Suitability of the models appeared to be influenced by texture type (coarse or fine textured soils) rather than by measured size ranges. SHIRAZI et al. (1988) established connections between texture classifications adopted by the USDA (Soil Survey Staff, 1975), the ISSS (1929) and the American Society of Civil Engineers (VANONI, 1980). This work was based on a description of the clay, silt and sand fractions by the geometric mean and the geometric standard deviation of their size ranges. BUCHAN et al. (1993) compared five different lognormal models for soil PSD. All five models accounted for more than $90 \%$ of the variance in the PSD of most of the examined soils. However, the algorithm did not converge for about $10 \%$ of the soils in their study. RAJKAI et al. (1996) applied logistic distribution functions to parameterize the particle-size distribution of Swedish soils, which was considered successful for $88 \%$ of the dataset. They also used a parameter estimation technique to obtain distribution parameters directly from measured particle-size data, without invoking a particular distribution function. NEMES et 
al. (1999) compared four methods to interpolate particle-size distributions. They concluded that - depending on the number and the position of the measured points - either fitting a non-parametric spline, or applying the so-called "similarity procedure" may offer the best solution. This procedure does not rely on mathematical interpolation but involves finding similar PSD curves in a sufficiently large external data set. MINASNY et al. (1999) developed an empirical model to convert the 2-20-2000 $\mu \mathrm{m}$ fraction scheme to the 2-50-2000 $\mu \mathrm{m}$ scheme to enable the testing of existing PTFs on Australian soil data. SKAGGS et al. (2001) suggest and test a generalized logistic model to estimate particlesize distribution from only clay, silt and fine plus very fine sand contents of the soil. The success of the method highly varies by texture classes, which correspond with the findings of others (e.g. RousSEVA, 1997). SHIRAZI et al. (2001) conclude that unifying the particle-size description into geometric mean and the geometric standard deviation of the particle-size offers a common language of soil texture research that is independent of classification systems. In practise, the loglinear interpolation has often been used to estimate missing particle-size classes for the FAO/USDA texture classification, but that method was shown to be unreliable by others (NEMES et al., 1999).

All of the above suggestions have their own difficulties and drawbacks. Some are less reliable for certain soil types than for others. Other studies found that prediction accuracy and model applicability rely rather on the number of measured points. Other suggestions require the collection of a large reference database. Considering the number of applied national and international classification systems, the number of unique combinations of points-to-be-predicted vs. available-measured-points on the PSD curve is very high, which may question the general applicability of many standardization methods.

To overcome the need for such methods, a new measurement equipment is proposed. It is based on the hydrometer theory, so it is compatible to the most commonly applied methods. It is computerized and enables multiple samples or replicates to be measured at the same time. Its need for manpower for operating it is limited to the conventional sample preparation of the hydrometer/pipette methods, which makes its use cost-effective and more importantly it may reduce human errors. In exchange, a quasi-continuous soil PSD curve is provided, which may be subject to any further analysis according to any classification system.

\section{Materials and Methods}

This method is based on the realization that changes in the average density of a suspension can be measured during the deposition of particles, where the density of particles is larger than the density of the liquid; and that deposition speed is dependent on the particle-size. The density of a suspension can be 
described with the measurement of the change of force derived from change of the hydrostatic pressure that acts on a cylinder sinking into the suspension.

Density of the suspension can be turned directly into digital signals with the use of an electric device that measures force, which practically can be an analytical scale. These signals are transmitted through a communication line into a computer. The computer accepts signals from multiple measurement cells in parallel. Data are evaluated quasi-continuously during the measurement as well as after the end of a measurement. Change of density as a function of time can be followed on screen from the beginning of the measurement, as well as the particle-size distribution calculated by an evaluation software. The evaluation software has been developed in Delphi development environment, so the look and feel of the resulting software is similar to other Windows based software. A theoretical outline of the equipment can be seen in Figure 1.

By calculating the speed of deposition of different particle-sizes, the relation between time and density of the suspension containing different particle-sizes can be calculated. The evaluating program needs to calculate this in a reverse direction. In the following the deduction of this relation will be briefly shown.

Reduction of lifting power that acts on the floating cylinder as a result of deposing particles needs to be taken into consideration during the calculations. Figure 2 shows the outline of the measurement cell. According to the law of Stokes, the deposition speed of particles can be unambiguously calculated from particle size and other constants of the system. Therefore it is satisfactory to calculate only the speed-concentration function of the system. This requires the following steps of calculation.

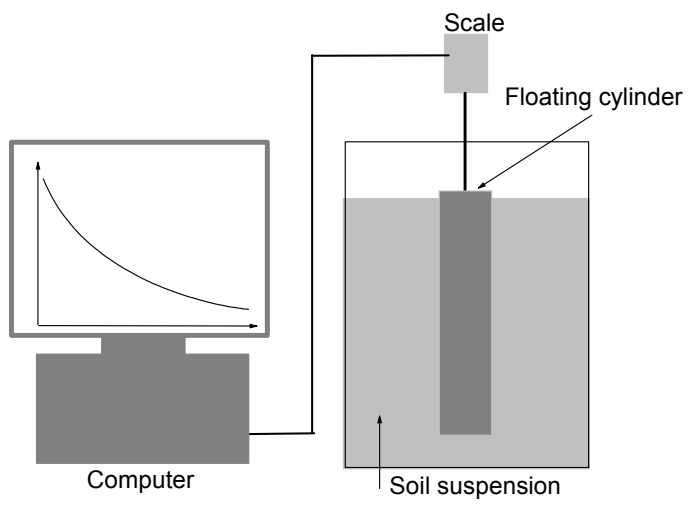

Figure 1

Scheme of the equipment

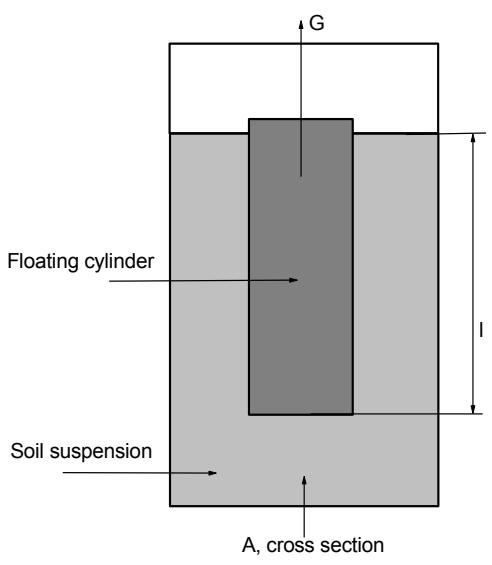

Figure 2

Theoretical outline of the measurement cell 
In a homogenous, monodispersed suspension, $G$ lifting power acts on a measurement cylinder with a given volume, as:

$$
G=A \cdot l \cdot g \cdot \rho
$$

where $A$ is the cross-section of the floating cylinder $\left(\mathrm{m}^{2}\right), l$ is the height of the floating cylinder $(\mathrm{m}), g$ is gravity acceleration $\left(9.81 \mathrm{~m} \cdot \mathrm{s}^{-2}\right)$, and $\rho$ is the density of the suspension $\left(\mathrm{kg} \cdot \mathrm{m}^{-3}\right)$.

Density of the suspension is determined by the density of the liquid, the density of suspended particles and the concentration of the suspended particles:

$$
\rho=\rho_{w}+c \cdot\left(\rho_{p}-\rho_{w}\right)
$$

where $\rho_{w}$ is the density of liquid $\left(\mathrm{kg} \cdot \mathrm{m}^{-3}\right), \rho_{p}$ is the density of suspended particles $\left(\mathrm{kg} \cdot \mathrm{m}^{-3}\right)$, and $c$ is the concentration of the suspended particles, $(\mathrm{kg} / \mathrm{kg})$.

When the particles in the suspension are settling with speed $v$, they move $v \cdot \Delta t$ distance downward during $t$ time. The concentration of the suspended particles changes $\Delta c$ around the measurement cylinder during this time:

$$
\Delta c=c \cdot \frac{l-v \cdot \Delta t}{l}
$$

This relationship can be interpreted only while the value of $v \cdot \Delta t$ does not exceed the height of the floating cylinder. Particles arriving lower than the bottom of the floating cylinder no longer influence the lifting power that acts on the floating cylinder. The above function would give zero instead of negative values, therefore the following correction is needed:

$$
\Delta c=c \cdot \frac{a b s(l-v \cdot \Delta t)+(l-v \cdot \Delta t)}{2 \cdot l}
$$

Lifting power changes during $t$ time which is related to the density change $(\Delta \rho)$ of the suspension in the following way:

$$
\Delta G=A \cdot l \cdot g \cdot \Delta \rho
$$

where:

$$
\Delta \rho=\left(\rho_{p}-\rho_{w}\right) \cdot c \cdot \frac{a b s(l-v \cdot \Delta t)+(l-v \cdot \Delta t)}{2 \cdot l}
$$

In a heterodispersed suspension the $i^{\text {th }}$ fraction from $n$ particle fractions of different size (sinking with different speed) causes $\Delta G_{i}$ change in lifting power during $t$ time.

$$
\Delta G_{i}=\frac{1}{2} \cdot A \cdot g \cdot\left(\rho_{p}-\rho_{w}\right) \cdot c_{i} \cdot\left[a b s\left(l-v_{i} \cdot \Delta t\right)+\left(l-v_{i} \cdot \Delta t\right)\right]
$$

The total change of lifting power in a heterogeneous suspension is the sum of changes for all fractions.

$$
\Delta G=\frac{1}{2} \cdot A \cdot g \cdot\left(\rho_{p}-\rho_{w}\right) \cdot \sum_{i=1}^{n}\left\{c_{i} \cdot\left[a b s\left(l-v_{i} \cdot \Delta t\right)+\left(l-v_{i} \cdot \Delta t\right)\right]\right\}
$$

During a measurement, $G$ is measured as a function of deposition time. Due to the large number of measurement points - provided by the possibility of using very small time steps - it is possible to determine the concentration of each fraction 
separately, described with $v_{i}$ deposition speed, using regression calculations. It is possible to define the proportion of more than hundred fractions of a sample, which provides a quasi-continuous curve of particle-size distribution.

\section{Results and Discussion}

To develop the algorithm, model experiments were carried out with simulation software. Relations between particle-size distributions and curves measured by the equipment are demonstrated. In Figure 3 particle-size distributions of three soil types extremely differing in soil texture (1. clay, 2. silt, 3. sand) and the sum of the 3 types can be seen, normalized for the integral value of the total particle-size area. Figure 4 presents measurement curves calculated for the same samples. It can be seen that samples of different particle-size distributions result in significantly different curves, which makes an unambiguous identification possible. Curves differ mainly in their slope. Relations of slope are given by the derivative function, related to the examined soil sample, as seen in Figure 3.

At present, only limited results are available. Curves from the examination of a soil sample are illustrated in Figure 5, as measured by the equipment. The upper curve shows how the density of the suspension decreased around the floating cylinder as a result of deposition. The lower wavier curve is derived from the upper line, using the theory outlined above.

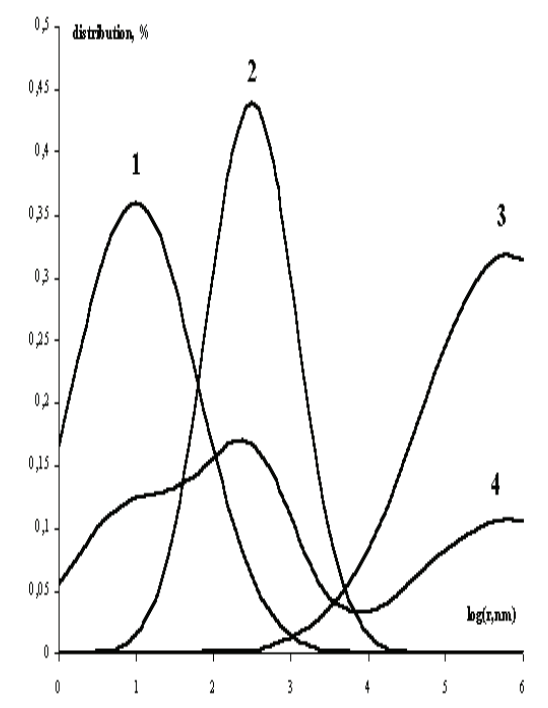

Figure 3

Three soil types extremely differing in soil texture (1. clay, 2. silt, 3. sand), and the sum (4.) of the three types normalized for the integral value of the total particle-size area 


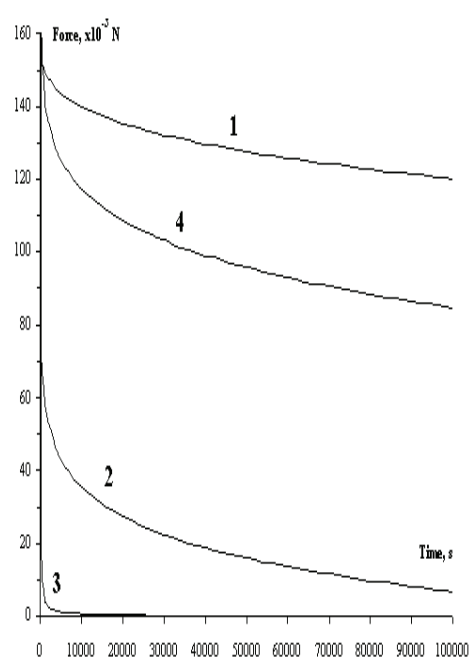

Figure 4

Measurement curves for the same particle-size distributions of Figure 3

(1. clay, 2. silt, 3. sand, 4. sum of the three types)

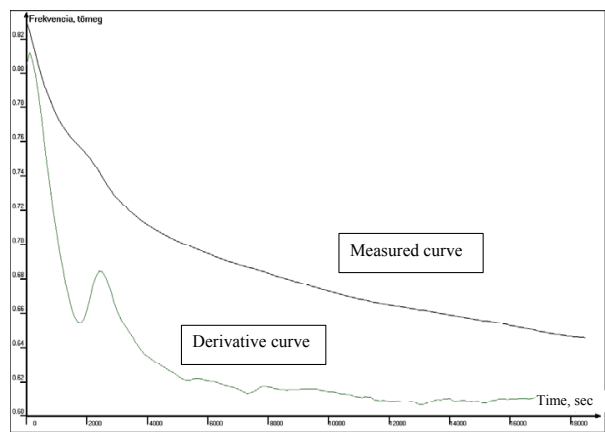

Figure 5

Measured and derived curves from the examination of soil sample GA/1.

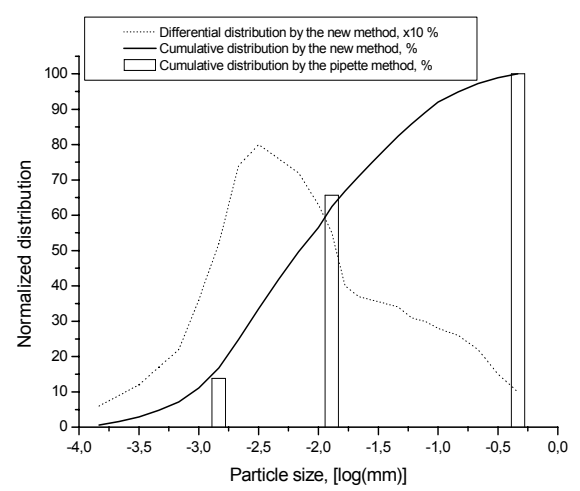

Figure 6

Comparison of measurements using the pipette method and the new automated technique

Figure 6 shows a comparison of measurements using the pipette method and the new equipment. Limitations are faced at the coarse end of the distribution curve when using any of the two methods, as particles of large sizes settle very quickly. The quasi-immediate settlement of particles larger than about $0.5 \mathrm{~mm}$ disables the performance of measurements (new technique) and/or proper sampling (pipette method). At the fine end of the PSD curve (clay) limitations 
are only measurement time and the need for detailed data. For practical purposes, in Figure 6, the measurement was stopped while particles of size $\sim 0.2 \mu \mathrm{m}$ settled. The presented preliminary data shows good correspondence with data measured at 2,20 and $500 \mu \mathrm{m}$ using the pipette method.

\section{Conclusions}

Based entirely on fundamental physical constants and equations a method was derived and modelled for the calculation of particle-size distribution using the density-time function of settling soil suspension. The lifting power acting on the floating cylinder is measured, which in turn allowed to design an equipment for the quasi-continuous particle-size analysis. The physical theory of the new system is similar to that of conventionally used systems, therefore data derived using this new system are comparable and compatible to data measured by the pipette or hydrometer methods. The only difference among the abovementioned methods is that particle-size distribution data measured by the new method are more precise and more detailed, therefore no interpolation is needed, no matter which classification system is to be matched. An approximate measurement range of $\sim 0.2 \mu \mathrm{m}$ to $\sim 500 \mu \mathrm{m}$ is feasible using the current settings, due to physical (immediate settlement) and practical (measurement time vs. required accuracy) limitations. However, increasing the density of the liquid phase above that of the conventional water-based solutions may provide the possibility of successfully measuring the distribution of coarser materials too.

Unification of different national particle-size classification systems is possible precisely with an equipment of continuous particle-size analysis. The quasi-continuous particle-size distribution curves, measured with this automated equipment, are suitable to fit with any national particle-size distribution categories, where otherwise possibilities of comparison are limited. With these results, errors of interpolated conversion are eliminated, making it possible to create international databases and maps, and to deduce more reliable conclusions than currently possible. More extended comparisons for the justification of this technique are necessary and are planned.

\section{Summary}

Soil texture is an important input parameter for many soil hydraulic pedotransfer functions (PTFs) of the day. Common soil particle-size classes are required to be able to uniformly determine the texture of soils. However, it is not always possible - due to different national classification systems - and much valuable information is disregarded while either deriving or applying PTFs. 
One way to get common particle-size class information is to interpolate the particle-size distribution (PSD) curve. Advanced interpolation solutions are becoming available, but there is always uncertainty associated with these techniques. Another possibility is to measure all PSD curves in such a way that it is compatible to the commonly used classification systems.

A new automated measurement technique is introduced that can easily provide PSD data compatible to any (and all) of the existing national and international classification systems at the same time, without the burden of extra labour. A computerized measurement system has been developed to record density changes in a settling-tube system in any discretional (small) time steps, which in turn allows the derivation of a quasi-continuous PSD curve. The measurement is based on areometry (Stokes-law), thus the system is compatible to the most commonly applied settling-tube measurements. The new evaluation method of measured values takes into consideration the density changes along the areometer-body so it avoids the problem of reference point determination. The theory and setup of the system are explained and measurement examples are given. The presented comparative measurements show good correspondence with conventional settling-tube results, and the reproducibility of the measurement shows to be very high. This technique does not require more sample preparation than past methods. The automated reading requires less manpower to perform the measurement - which also reduces human error sources. However, it provides very detailed PSD data that has advantages, like revealing multi-modality in the particle-size distribution or providing data that complies with any of the classification systems.

Key words: soil texture, particle-size distribution, pedotransfer functions, automated, aerometry

The presented work was supported by the National Scientific Research Fund under grant No. T 32506.

\section{References}

Buchan, G. D., 1989. Applicability of the simple lognormal model to particle-size distribution in soils. Soil Sci. 147. (3) 155-161.

BuChAN, G. D., GREwAL K. S. \& RoBSON, A. B., 1993. Improved models of particlesize distribution: An illustration of model comparison techniques. Soil Sci. Soc. Am. J. 57. 901-908.

Campbell, G. S., 1985. Soil Physics with BASIC. Developments in Soil Science. 14. Elsevier, Amsterdam.

FAO (Food and Agriculture Organisation), 1990. Guidelines for Soil Descriptions. (3rd ed.). FAO/ISRIC, Rome.

FILEP, G. \& FERENCZ, G., 1999. Recommendation for improving the accuracy of soil classification on the basis of particle composition. Agrokémia és Talajtan, 48. 305-320. 
Gee, G. W. \& BAuder, J. W., 1986. Particle-size analysis. In: Methods of Soil Analysis. Part 1. (Ed.: KLUTE, A.) 383-411. ASA-SSSA. Madison, Wisc.

International Society of Soil Science (ISSS), 1929. Minutes of the first Commission Meetings, Intl. Congress of Soil Science, Washington, 1927. Proc. Congr. ISSS. 4. 215-220.

KATSCHINSKI, N. A., 1956. Die mechanische Bodenanalyse und die Klassifikation der Böden nach ihrer mechanischen Zusammensetzung. Rapports au Sixiéme Congrés de la Science du Sol. Paris, B, 321-327.

Minasny, B., McBRATney A. B. \& BRistow, K. L., 1999. Comparison of different approaches to the development of pedotransfer functions for water-retention curves. Geoderma. 93. 225-253.

Nemes, A. et al., 1999. Evaluation of different procedures to interpolate particle-size distributions to achieve compatibility within soil databases. Geoderma. 90. 187-202.

OliveIRA, J. C. M. et al., 1997. Improved soil particle-size analysis by gamma ray attenuation. Soil Sci. Soc. Am. J. 61. 23-26.

RAJKAI, K. et al., 1996. Estimation of water-retention characteristics from the bulk density and particle-size distribution of Swedish soils. Soil Sci. 161. (12) 832-845.

Rousseva, S. S., 1987. Studies on the soil erodibility of calcaric chernozems and cinnamonic forest soils. (In Bulgarian). Ph.D. Thesis, N. Poushkarov Institute of Soil Science, Academy of Agricultural Sciences. Sofia

RousSEVA, S. S., 1997. Data transformations between soil texture schemes. European J. Soil Sci. 48. 749-758.

ShIRAZI, M. A. \& BOERSMA, L., 1984. A unifying quantitative analysis of soil texture. Soil. Sci. Soc. Am. J. 48. 142-147.

SHIRAZI, M. A., BOERSMA, L. \& HART, J. W., 1988. A unifying quantitative analysis of soil texture: Improvement of precision and extension of scale. Soil Sci. Soc. Am. J. 52. $181-190$.

ShirAzi, M. A., Boersma, L. \& Johnson, C. B., 2001. Particle-size distributions: Comparing texture systems, adding rock, and predicting soil properties. Soil Sci. Soc. Am. J. 65. 300-310.

SkAGGS, T. H. et al., 2001. Estimating particle-size distribution from limited soil texture data. Soil Sci. Soc. Am. J. 65. 1038-1044.

Soil Survey Staff, 1975. Soil Taxonomy: A Basic System of Soil Classification for Making and Interpreting Soil Surveys. USDA/SCS Agricultural Handbook No. 436. U.S. Gov. Print. Office. Washington, D. C.

Soil Survey Staff, Soil Conserv. Service, 1991. State Soil Geographic Data Base (STATSGO), Data User Guide. Misc. Publ. 1492. U.S. Gov. Print. Office. Washington, D. C.

STARR, G. C. et al., 2000. Soil particle concentrations and size analysis using a dielectric method. Soil Sci. Soc. Am. J. 64. 858-866.

StUYT, L. C. P. M., 1992. The water acceptance of wrapped subsurface drains. Ph.D. Thesis. Agricultural University of Wageningen, The Netherlands. (LU-1468)

USDA (United States Department of Agriculture), 1951. Soil Survey Manual. U.S. Dept. Agriculture Handbook No. 18. Washington, D. C.

VANONI, V. A., 1980. Sedimentation Engineering. Sedimentation Committee, Hydraulic Division, American Society of Civil Engineers. New York.

WALKER, P. H. \& ChitTleborough, D. J., 1986. Development of particle-size distribution in some Alfisols of southeastern Australia. Soil. Sci. Soc. Am. J. 50. 394-400. 